\title{
Effectiveness and economic impact of a diabetes education program among adults with type 2 diabetes in South Texas
}

\author{
Matthew Lee Smith ${ }^{1,2^{*}}$, Lixian Zhong ${ }^{1,3}$, Shinduk Lee ${ }^{1,4}$, Samuel D. Towne $\mathrm{Jr}^{1,2,5,6,7}$ and Marcia G. Ory ${ }^{1,2}$
}

\begin{abstract}
Background: The long-term growth and sustained high prevalence of obesity in the US is likely to increase the burden of Type 2 diabetes. Hispanic individuals are particularly burdened by a larger share of diabetes than nonHispanic White individuals. Given the existing health disparities facing this population, we aimed to examine the effectiveness and potential cost savings of the Diabetes Education Program (DEP) offered as part of Healthy South Texas, a state-legislated initiative to reduce health disparities in 27 counties in South Texas with a high proportion of Hispanic adults.
\end{abstract}

Methods: DEP is an 8-h interactive workshop taught in English and Spanish. After the workshop, participants receive quarterly biometric screenings and continuing education with a health educator for one year. Data were analyzed from 3859 DEP participants with Type 2 diabetes living in South Texas at five time points (baseline, 3months, 6-months, 9-months, 12-months). The primary outcome variable of interest for study analyses was A1c. A series of independent sample t-tests and linear mixed-model regression analyses were used to identify changes over time. Two methods were then applied to estimate healthcare costs savings associated with A1c reductions among participants.

Results: The majority of participants were ages 45-64 years (58\%), female (60\%), Hispanic (66\%), and had a high school education or less (75\%). At baseline, the average hemoglobin A1c was $8.57 \%$. The most substantial reductions in hemoglobin $A 1 \mathrm{c}$ were identified from baseline to 3-month follow-up $(P<0.001)$; however, the reduction in A1c remained significant from baseline to 12-month follow-up $(P<0.001)$. The healthcare cost savings associated with improved A1C for the program was estimated to be between $\$ 5.3$ to $\$ 5.6$ million over a two to three year period.

Conclusion: Findings support the effectiveness of DEP with ongoing follow-up for sustained diabetes risk management. While such interventions foster clinical-community collaboration and can improve patient adherence to recommended lifestyle behaviors, opportunities exist to complement DEP with other resources and services to enhance program benefits. Policy makers and other key stakeholders can assess the lessons learned in this effort to tailor and expand similar initiatives to potentially at-risk populations.

\footnotetext{
* Correspondence: matthew.smith@tamu.edu

'Center for Population Health and Aging, Texas A\&M University, College Station, TX 77843, USA

${ }^{2}$ Department of Environmental and Occupational Health, School of Public Health, Texas A\&M University, College Station, TX 77843, USA

Full list of author information is available at the end of the article
}

(c) The Author(s). 2021 Open Access This article is licensed under a Creative Commons Attribution 4.0 International License, which permits use, sharing, adaptation, distribution and reproduction in any medium or format, as long as you give appropriate credit to the original author(s) and the source, provide a link to the Creative Commons licence, and indicate if changes were made. The images or other third party material in this article are included in the article's Creative Commons licence, unless indicated otherwise in a credit line to the material. If material is not included in the article's Creative Commons licence and your intended use is not permitted by statutory regulation or exceeds the permitted use, you will need to obtain permission directly from the copyright holder. To view a copy of this licence, visit http://creativecommons.org/licenses/by/4.0/. The Creative Commons Public Domain Dedication waiver (http://creativecommons.org/publicdomain/zero/1.0/) applies to the data made available in this article, unless otherwise stated in a credit line to the data. 
Trial registration: This community-based intervention is not considered a trial by ICMJE definitions, and has not be registered as such.

Keywords: Diabetes education, Economic evaluation, Disease management, Community intervention

\section{Background}

In 2018, more than 34 million Americans were estimated to have diabetes [1]. Further, there are an additional 88 million American adults estimated to have pre-diabetes in 2018 [1]. By 2060, prevalence of diagnosed Type 2 diabetes is expected to increase to 60.6 million among American adults [2]. This is driven, in part, by the rising rates of obesity, which is estimated to be approximately $42 \%$ [3]. Hispanic adults have higher rates of obesity and Type 2 diabetes than non-Hispanic White adults [4-6]. The likelihood of developing Type 2 diabetes among Hispanic individuals is 50\% more than that of the average adult in the US [4]. These existing health inequalities make Hispanic individuals more susceptible to diabetes-related complications and an important population to receive diabetes management interventions.

People living with diabetes are at a greater risk of experiencing various diabetes-related complications (e.g., vision loss, nephropathy, and neuropathy) [7], lower quality of life $[8,9]$, and premature death $[10,11]$. Healthcare expenditures for people with diabetes are almost two times higher than the healthcare expenditures for people without diabetes [12]. In 2017, the estimated economic cost of diabetes was $\$ 327$ billion, which was substantially higher than the estimated cost of $\$ 245$ billion in 2012 [13]. As such, diabetes in the US is a growing concern for individuals and their families as well as communities and other key stakeholders seeking to reduce the economic burden of diabetes throughout the US. Again, this underscores the urgent need to develop, deliver, and support diabetes interventions that can help susceptible and high-risk populations manage their diabetes.

Managing one's blood glucose level is essential to diabetes care and self-management because it is associated with better health outcomes and reduced healthcare costs $[13,14]$. An individual's hemoglobin A1c value reflects their average blood glucose levels over approximately three months [15], and a higher A1c value indicates higher blood glucose level. A normal A1c level (measured in \%) is below 5.7\% [15], and American Diabetes Association (ADA) recommends A1c value below $7 \%$ for adults in general [4]. Unfortunately, about half of American adults with diagnosed diabetes have A1c value of $7.0 \%$ or higher [16]. Prior studies showed that reduction in A1c among people with diabetes can reduce risk of diabetic complications and healthcare cost $[17,18]$.
While interventions such as diabetes self-management education and support (DSMES) have been shown to improve diabetes self-management knowledge and skills $[19,20]$, they have also been successful to reduce A1c among participants [21-23]. Despite known benefits of DSMES, such programs are not always available or delivered in high-risk areas with disproportionate rates of obesity, pre-diabetes, and Type 2 diabetes [24, 25]. One such area with elevated diabetes risk is South Texas, a region of 27 counties near the Texas-Mexico border. In 2016, county-level prevalence of diabetes in the 27county region ranged from 3.4 to $24.2 \%$ and 15 of the 27 counties had higher diabetes prevalence rate than the national prevalence rate of $10.2 \%$ [24, 25]. In this region, diabetes rates are among the highest in the US, which are largely attributed to the lack of healthcare resources needed [26]. As such, it important to deliver diabetes interventions in these underserved areas with high-risk populations as well as evaluate the effectiveness and impact such interventions have on individual and community health.

While DSMES has been offered in the South Texas region for the past two decades in the form of the Diabetes Education Program (DEP), its impact and cost effectiveness are not fully understood. Despite serving thousands of residents over time in this region, only limited evaluations of its impact have been performed [27]. In this context, the purposes of this study were to examine the changes in A1c and associated potential healthcare cost savings related to DEP implementation in South Texas among highly susceptible populations as part of the Healthy South Texas initiative.

\section{Methods}

\section{Program description}

The Healthy South Texas initiative was initiated in September of 2015 as a collaborative effort between government, academic, clinical, and community organizations to alleviate the impact of chronic and acute diseases throughout 27 South Texas counties [28]. Funded by the State of Texas on a biannual basis, this initiative integrated efforts between the Texas A\&M Health Science Center and the Texas A\&M Agrilife Extension System, and a primary focus was diabetes prevention and management. A hallmark program was the DEP, which was developed approximately 20 years ago by the Coastal Bend Health Education Center [29]. 
DEP is an ADA-recognized DSMES [29], which consists of an 8-h interactive workshop and four quarterly follow-up sessions (at 3, 6, 9, and 12 months). Available in either English or Spanish, the small group, 8-h interactive workshop was primarily delivered to participants during one full day; however, workshops are also commonly delivered as a series (e.g., two 4-h workshop sessions or four 2-h workshop sessions). One or more facilitators leads the workshop, and at least one facilitator was required to be a registered nurse, registered dietitian, pharmacist, or a certified diabetes educator. DEP was originally developed by a bilingual and bicultural team, along with community and clinical advisors, to ensure the program was culturally appropriate for target audiences. While the program was not specifically translated into Spanish, bilingual DEP facilitators led workshops for Spanish-speaking participants. Topics covered during DEP included diabetes and diabetes complications, blood glucose monitoring, diet, medication, physical activity, stress management and goal setting [27, 29]. Table 1 provides an overview of DEP in terms of topics of discussion and the amount of time spent on each topic. Each quarterly follow-up visit involved a brief one-on-one session between the participant and the DEP workshop leader to discuss the participant's diabetes management goals and barriers and solutions to meet the goals. These follow-up sessions also included a brief data collection of A1c and other biometrics screenings.

\section{Participants and recruitment procedures}

Participants with pre-diabetes and diabetes were invited to participate in the program. Based on the communitybased nature of this initiative, those without pre-diabetes or diabetes were also welcome to attend workshops; however, their data were not used for research purposes. Participants were recruited through recommendations and referrals from partnering healthcare systems and community-based organizations as well as through community health screening and educational events. Physical and electronic recruitment materials (e.g., flyers, social media) were also circulated, and self-referrals were

Table 1 Overview of Diabetes Education Program agenda (delivered in one full day)

\begin{tabular}{|c|c|}
\hline Time & Topic of Discussion \\
\hline \multirow[t]{4}{*}{$30 \mathrm{~min}$} & Data Collection: \\
\hline & - Registration Forms \\
\hline & - Pre-Test Instrument \\
\hline & - Biometrics (e.g., A1c, blood pressure) (continues through the morning) \\
\hline $15 \mathrm{~min}$ & Introductions and Welcome \\
\hline \multirow[t]{2}{*}{$1.25 \mathrm{~h}$} & Diabetes Overview: \\
\hline & - Preventing Short- and Long-Term Complications \\
\hline $15 \min$ & Break \\
\hline \multirow[t]{4}{*}{$1.75 \mathrm{~h}$} & - Nutrition \\
\hline & • Meal Planning \\
\hline & - Basic Carbohydrate Counting \\
\hline & - Label Reading \\
\hline $30 \mathrm{~min}$ & Working Lunch \\
\hline $45 \mathrm{~min}$ & Medications \\
\hline $30 \mathrm{~min}$ & Highs, Lows, and Sick Days \\
\hline $15 \min$ & Introductions to Blood Glucose Meters \& Monitoring (pre-exercise) \\
\hline $15 \min$ & Physical Activity: "Walking Down Your Blood Sugar" \\
\hline $15 \min$ & Monitoring (post-exercise) \\
\hline $15 \mathrm{~min}$ & Break \\
\hline $15 \min$ & Foot Care \\
\hline $30 \mathrm{~min}$ & Life Stresses, Diabetes Stresses, Depression \\
\hline $30 \mathrm{~min}$ & Recommended Values \\
\hline \multirow[t]{3}{*}{$30 \mathrm{~min}$} & Goal Setting Activity \\
\hline & Post-Test Instrument \\
\hline & Course Evaluation \\
\hline
\end{tabular}


accepted. Workshops were held in a variety of venues deemed to be convenient for participants to reduce burdens associated with transportation (e.g., healthcare settings, community centers, county offices) [30]. There was no charge to the participant for attending the DEP. The Coastal Bend Health Education Center consented participants to attend this community-based intervention and have their data used for evaluation purposes. Informed consent was obtained from all participants. Participant consent included information collected from participants during the intervention (i.e., registration forms, surveys, attendance, and biometric information), but did not include any information from their hospital records or claims data. This study involved retrospective reviews and data analyses and was reviewed and approved by the Institutional Review Board at Texas A\&M University (IRB2019-0225D).

\section{Geospatial target area}

Participants resided in multiple counties from the South Texas region; however, the majority lived within three counties. Over half of the participants resided in Nueces County, of which $63 \%$ were Hispanic and $11 \%$ had diabetes in 2018 [31]. The next largest segment of participants resided in Victoria County and Kleberg County, where the Hispanic population accounts for approximately 46 and $73 \%$ respectively, with a diabetes prevalence of 11 and 9\% respectively in 2018 [31]. Given about $39 \%$ of all Texans are Hispanic and approximately $10 \%$ had diabetes statewide in 2018, this geographic area may carry disproportionate diabetes-related burdens and elevated risk for related complications. In light of this information, targeting residents of the South Texas region with a program addressing Type 2 diabetes was particularly relevant and timely.

\section{Measures}

The primary outcome of interest was hemoglobin A1c levels (measured in \% units). The health assessments were performed at baseline and each follow-up at 3, 6, 9, and 12 months. Participant characteristics were recorded in the participant registration form and included age (18-44, 45-64 and 65+), sex (male and female), race/ ethnicity (non-Hispanic White, non-Hispanic Black, Hispanic, and other or multiple races), education (no high school, high school/GED, Associate's degree, Bachelor's degree, and graduate degree), insurance status (private insurance, Medicaid, Medicare, other insurance, and no insurance), smoking status (yes or no), and alcohol consumption status (yes or no). Diabetes characteristics (e.g., type) were also self-reported during the assessment.

\section{Statistical analysis}

Baseline characteristics of program participants with Type 2 diabetes were described. Participant characteristics (categorical variables) were compared using Chi-squared tests based on whether they attended follow-up sessions at 3 months and 12 months. Post-workshop A1c changes at 3month, 6-month, 9-month, and 12-month follow-up were compared to baseline using paired 2-sample t-tests. Linear mixed models with participant-level random intercepts were fitted for continuous outcome variables (A1c) controlling for covariates including age, sex, race/ethnicity, education, insurance status, and health behaviors (smoking and alcohol consumption). Linear mixed regression models were conducted using Stata SE14 (Stata Corporation, College Station, TX) using the "mixed" command. Statistical significance for all analyses was determined using the criterion of $p<0.05$.

\section{Economic evaluation}

Two methods were applied to estimate healthcare costs savings associated with A1c reductions observed from this initiative. Method 1 adopted Bansal and colleagues [32] approach and estimated healthcare cost savings associated with A1c reduction among participants with a baseline A1c $\geq 9 \%$. In this study, Bansal and colleagues [32] utilized a large US health plan administrative claims database to analyze cost savings associated with A1c reduction over a 2-year period. The initial data source included more than 6 million members from the Optum Clinformatics Data Mart database with linked lab values (OptumInsight, Eden Prairie, MN, USA). From these data, 3197 eligible diabetes patients with initial A1c $\geq 9 \%$ were identified and categorized into two groups: decreasers (i.e., whose A1c decreased by any amount during the 1-year post-education period) and non-decreasers (i.e., whose A1c increased or did not change). Healthcare costs were compared between a matched sample of 912 decreasers and 912 non-decreasers based on 2014 US Dollars. The study found that patients in the decreaser group averaged a $24 \%$ (\$2503) reduction of healthcare costs in the first year of follow-up and 17\% (\$1690) reduction in the second year. The cost categories included inpatient, outpatient, emergency department, pharmacy, and other costs. These per-patient cost savings were adopted in our study and were multiplied by the number of eligible patients to estimate the cost savings associated with the DEP over a two-year time period. Two types of cost savings were estimated: 1) cost savings from followed participants at 12 months; and 2) cost-savings extrapolated to the entire program participants, including those lost to follow-up. The cost-savings from followed participants at 12 months were directly computed by multiplying the per-patient cost savings by the number of participants with baseline A1c $\geq 9 \%$ and A1c 
reduction at 12-month follow-up. To estimate the cost savings for the entire program, we first calculated the proportion of Type 2 diabetes participants with reduction of A1c (decreasers) based on 12-month follow-up data among participants with baseline $\mathrm{A} 1 \mathrm{C} \geq 9 \%$. This proportion was then applied to the program participants with baseline $\mathrm{A} 1 \mathrm{C} \geq 9 \%$ to estimate the number of eligible participants for cost savings. Although DEP data were only collected over a 12-month period, we estimated the potential 1-year and 2-year healthcare cost savings for this sample based on assumptions in savings similar to what Bansal and colleagues reported [31].

Method 2 was based on Glimer and colleagues [33], which assessed the impact of A1c change on healthcare costs among patients with diabetes. The study prospectively followed 1694 diabetes patients via a patient survey, which were then merged with a medical record review. Multivariate generalized linear regression analysis was conducted to predict cost differentials for $1 \%$ changes in A1c over a 3-year period. Costs were originally reported in 2002 US Dollars. The study found increasing cost differentials associated with $1 \%$ change of A1c as A1c levels increased. The study reported an average per patient cost saving of $\$ 1374$ for A1c change from 10 to $9 \%$, $\$ 1303$ from 9 to $8 \%, \$ 373$ from 8 to $7 \%$, and $-\$ 514$ from 7 to $6 \%$ in the overall diabetes patient population. In our study, we evaluated the 12-month follow-up A1c change from baseline for each participant and segmented the change into $1 \%$ intervals (A1c $<7,7 \% \leq \mathrm{A} 1 \mathrm{c}<8,8 \% \leq$ A1c $<9,9 \% \leq \mathrm{A} 1 \mathrm{c}<10 \%, \mathrm{~A} 1 \mathrm{c} \geq 10 \%)$. Cost savings for that particular participant were estimated to be a linear combination of cost savings in each segment. For example, if a participant had a baseline A1c of $9.5 \%$ and a 12-month follow-up A1c of 7.5\%, the participant would be assigned a cost-saving of $(\$ 373)^{*} .5+(\$ 1303)^{*} 1+$ $(\$ 1374)^{*} 0.5=\$ 2176.50$.

Because Glimer and colleagues [33] capped cost savings at A1c levels of $10 \%$, and our data reported A1c reductions in the $\geq 10 \%$ range, we extrapolated the cost savings by carrying forward the $\$ 1374$ per $1 \%$ reduction to participants with to $\mathrm{A} 1 \mathrm{c} \geq 10 \%$. For example, if a participant had a baseline A1c of $12 \%$, and a 12-month follow-up A1C of $8.5 \%$, they would be assigned a cost-saving of $(\$ 1374)^{*}[2]+$ $(\$ 1374)^{*} 1+(\$ 1303)^{*}(0.5)=\$ 4773.5$. The impact of A1c change on healthcare costs in both directions were considered. If a participant had an A1c increase at 12-month follow-up compared to baseline, then the sign would be reversed to reflect the cost differential. After estimating all participant's cost savings based on their 12-month follow-up, average cost-savings were calculated based on baseline A1c distribution in the following categories (A1c $<7,7 \% \leq \mathrm{A} 1 \mathrm{c}<8,8 \% \leq \mathrm{A} 1 \mathrm{c}$ $<9,9 \% \leq \mathrm{A} 1 \mathrm{c}<10 \%$, and $\mathrm{A} 1 \mathrm{c} \geq 10 \%)$.
For Method 2, two of cost savings were estimated: 1) cost-savings from followed participants at 12-month follow-up; and 2) cost savings extrapolated to the entire program participants including those lost to follow-up. To estimate the potential cost savings for the entire program, the proportion of participants' baseline A1c distribution based on these A1c intervals were computed and applied to the average cost savings to generate a weighted average cost saving per participant. This weighted average cost saving per participant was then multiplied by the number of Type 2 diabetes patients who enrolled in the program at baseline.

For both Method 1 and Method 2 used in this study, all costs savings were inflated to 2018 US Dollars based on consumer price index (CPI) for medical care services. Discounting was not applied given the relative short time horizon of the program. Costs in 2018 US Dollars was used based on the most recent year of DEP data collected for these analyses.

\section{Results \\ Sample follow-up and characteristics}

Between September 1, 2015 and July 31, 2018, a total of 5907 participants enrolled in DEP. The majority $(n=$ 3859) had Type 2 diabetes and 681 had pre-diabetes at baseline. The participants flow from baseline to 3-, 6-, 9, and 12-month follow-ups are presented in Fig. 1. Table 2 presents the characteristics of these patients at baseline, 3-month follow-up, and 12-month follow-up. At baseline, most program participants were between the ages of 45 and 64 (58\%), female (60\%), Hispanic (66\%), and had a high school education or less (75\%). Most participants (81\%) had insurance coverage, with $49 \%$ being covered by private insurance. Large proportions of participants did not smoke (89\%) and did not consume alcohol (74\%). The baseline average A1c level was $8.52 \%( \pm 2.26 \%)$.

\section{Unadjusted A1c changes}

A1c changes from baseline at 3-, 6-, 9-, and 12-month follow-up are presented in Fig. 2. Participants showed statistically significant A1c reductions across all followup time points. On average, participants had a $0.90 \%$ point reduction of A1c at 3 months $(p<0.001)$, followed by $0.77 \%$ point reduction at 6 months $(p<0.001), 0.84 \%$ point at 9 months $(p<0.001)$, and $0.62 \%$ points at 12 months $(p<0.001)$.

\section{Adjusted A1c changes}

Table 3 reports the A1c improvements between baseline and follow-ups after adjusting for covariates (i.e., age, sex, race/ethnicity, education, insurance type, smoking status, and alcohol consumption) using a linear mixed regression model. Statistically significant adjusted 


\section{5,907 participants enrolled in the study}

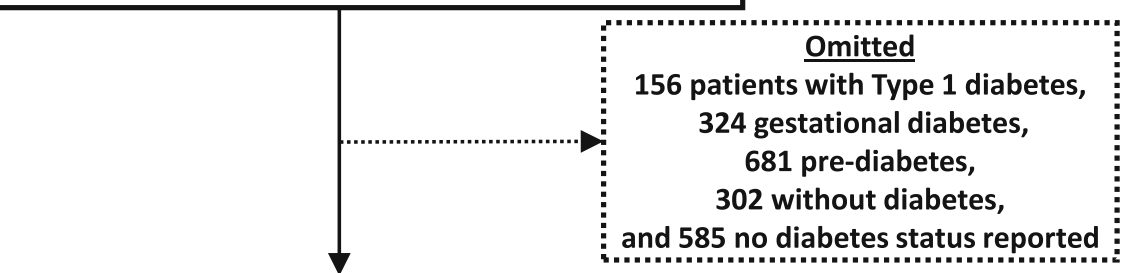

3,859 with Type 2 diabetes

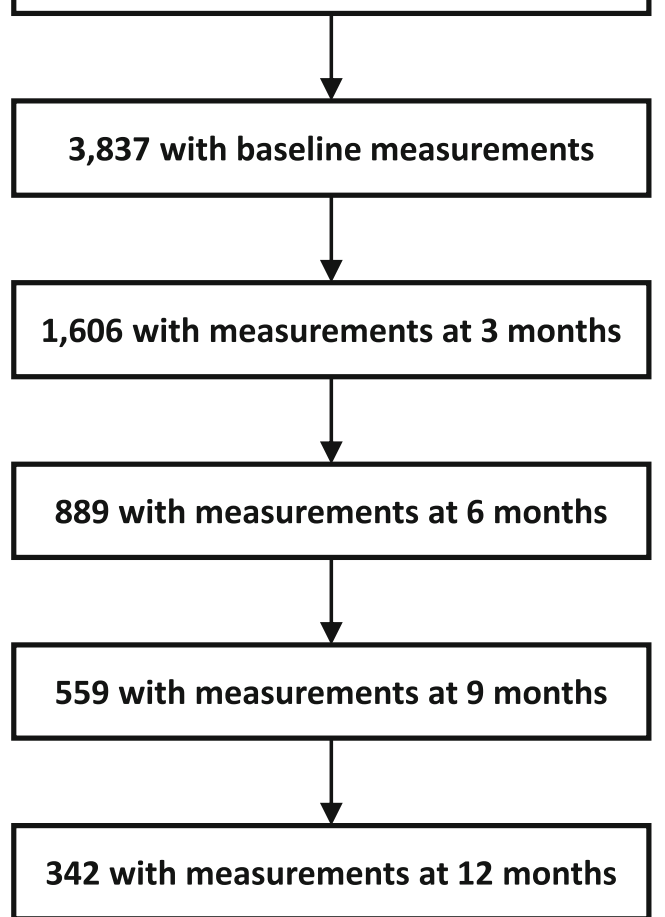

Fig. 1 Flow chart of participants in the Diabetes Education Program from baseline to 12-months

changes were detected. The adjusted A1c reductions were $0.93 \%$ points at 3 months $(p<0.001), 0.83 \%$ points at 6 months $(p<0.001), 0.87 \%$ points at 9 months $(p<$ $0.001)$, and $0.73 \%$ points at 12 months $(p<0.001)$.

\section{Economic impact evaluation}

Table 4 reports the estimated healthcare cost savings from A1c reductions for the first and second year following DEP participation using the Bansal et al. [31] approach. The cost savings per patient were $\$ 2780$ in the first year and \$1877 in the second year among participants with baseline A1c of $9 \%$ and above. Of the 3859 Type 2 diabetes participants who enrolled in DEP, 1375 (35.63\%) had baseline A1c $\geq 9 \%, 1152$ (83.75\%) of which were estimated to have decreased A1c at 12-month follow-up. The cost savings of the T2DM participant based on 12-month follow-up was estimated to be $\$ 186$ $\mathrm{K}$ in the first year and $\$ 126 \mathrm{~K}$ in the second year. When extrapolated to the total number of qualified program participants, the total cost savings of DEP were estimated to be $\$ 3.2$ million in the first year and an additional $\$ 2.2$ million in the second year.

Table 5 reports the estimated healthcare cost savings from A1c reductions in three years post DEP participation using the Glimer et al. [33] approach. The average cost savings per participant were estimated by initial A1c levels (i.e., <7\%, 7-8\%, 8-9\%, 9-10\%, and $\geq 10 \%$ ) based on 12-month follow-up data. The weighted average cost saving was $\$ 1501$ per participant, and the total program healthcare cost saving of the 3859 Type 2 diabetes participants who enrolled in DEP was estimated to be $\$ 5.8$ million for three years in 2018 US Dollars. 
Table 2 Characteristics of participants at baseline, 3 months, and 12 months

\begin{tabular}{|c|c|c|c|c|c|c|c|}
\hline & $\begin{array}{l}\text { Baseline } \\
(n=3837) \\
\text { n () }\end{array}$ & $\begin{array}{l}\text { 3-mo assessment } \\
(n=1606) \\
n()\end{array}$ & $\begin{array}{l}\text { no 3-mo assessment } \\
(n=2231) \\
n(\%)\end{array}$ & $P$ & $\begin{array}{l}\text { 12-mo assessment } \\
(n=342) \\
n(\%)\end{array}$ & $\begin{array}{l}\text { no } 12 \text {-mo assessment } \\
(n=3495) \\
n(\%)\end{array}$ & $\mathbf{P}$ \\
\hline Sex & & & & 0.339 & & & 0.612 \\
\hline Male & $1546(40.35)$ & $660(41.25)$ & $886(39.71)$ & & $142(41.64)$ & $1404(40.23)$ & \\
\hline Female & 2285 (59.65) & $940(58.75)$ & $1345(60.29)$ & & 199 (58.36) & $2086(59.77)$ & \\
\hline Race/Ethnicity & & & & $<0.001$ & & & $<0.001$ \\
\hline Non-Hispanic Black & $131(3.43)$ & $47(2.94)$ & 84 (3.79) & & $10(2.92)$ & $121(3.48)$ & \\
\hline Hispanic & $2513(65.80)$ & $984(61.46)$ & $1529(68.94)$ & & $175(51.17)$ & $2338(67.24)$ & \\
\hline Non-Hispanic White & $1057(27.68)$ & $519(32.42)$ & $538(24.26)$ & & $144(42.11)$ & $913(26.26)$ & \\
\hline Other/Multiple Races & $118(3.09)$ & $51(3.19)$ & $67(3.02)$ & & $13(3.80)$ & $105(3.02)$ & \\
\hline Age & & & & $<0.001$ & & & $<0.001$ \\
\hline $18-44$ & $558(14.54)$ & $187(11.64)$ & $371(16.63)$ & & $30(8.77)$ & $528(15.11)$ & \\
\hline $45-64$ & $2209(57.57)$ & 931 (57.97) & $1278(57.28)$ & & $174(50.88)$ & $2035(58.23)$ & \\
\hline $65+$ & $1070(27.89)$ & 488 (30.39) & $682(26.09)$ & & $138(40.35)$ & $932(26.67)$ & \\
\hline mean (std. dev.) & $57.10( \pm 12.23)$ & $58.32( \pm 11.63)$ & $56.22( \pm 12.57)$ & & $60.76( \pm 11.39)$ & $56.74( \pm 12.25)$ & \\
\hline Education & & & & $<0.001$ & & & 0.003 \\
\hline No High School (HS) & $513(16.99)$ & 179 (14.49) & 334 (18.71) & & $31(13.14)$ & $482(17.31)$ & \\
\hline HS/GED & $1760(58.28)$ & $697(56.44)$ & $1063(59.55)$ & & $123(52.12)$ & $1637(58.80)$ & \\
\hline Associate & $321(10.63)$ & $155(12.55)$ & $166(9.30)$ & & $38(16.10)$ & $283(10.17)$ & \\
\hline Bachelors & $250(8.28)$ & $121(9.80)$ & $129(7.23)$ & & 29 (12.29) & $221(7.94)$ & \\
\hline Graduate & $176(5.83)$ & $83(6.72)$ & $93(5.21)$ & & $15(6.36)$ & $161(5.78)$ & \\
\hline Insurance & & & & $<0.001$ & & & $<0.001$ \\
\hline Private & $1868(48.80)$ & $872(54.43)$ & $996(44.74)$ & & $215(63.24)$ & 1653 (47.39) & \\
\hline Medicaid & $109(2.85)$ & $34(2.12)$ & $75(3.37)$ & & $2(0.59)$ & $107(3.07)$ & \\
\hline Medicare & 754 (19.70) & $300(18.73)$ & $454(20.40)$ & & $72(21.18)$ & $682(19.55)$ & \\
\hline Other & $317(8.28)$ & $84(5.24)$ & $233(10.47)$ & & $5(1.47)$ & $312(8.94)$ & \\
\hline No insurance & $780(20.38)$ & $312(19.48)$ & $468(21.02)$ & & $46(13.53)$ & $734(21.04)$ & \\
\hline Smoke & & & & 0.005 & & & 0.000 \\
\hline Yes & $402(10.53)$ & $142(8.89)$ & $260(11.70)$ & & $14(4.12)$ & $392(11.20)$ & \\
\hline No & $3417(89.47)$ & $1455(91.11)$ & $1962(88.30)$ & & $326(95.88)$ & $3109(88.80)$ & \\
\hline Drink Alcohol & & & & 0.027 & & & 0.762 \\
\hline Yes & $1002(26.35)$ & 449 (28.22) & $553(25.01)$ & & $87(25.66)$ & 915 (26.42) & \\
\hline No & $2800(73.65)$ & $1142(71.78)$ & $1658(74.99)$ & & $252(74.34)$ & $2548(73.58)$ & \\
\hline A1c (mean (std. dev.)) & $8.52( \pm 2.26)$ & $7.41( \pm 1.69)$ & $\mathrm{n} / \mathrm{a}$ & & $7.309( \pm 1.59)$ & $\mathrm{n} / \mathrm{a}$ & \\
\hline
\end{tabular}

n/a not applicable

\section{Discussion}

This study presented changes in A1c among DEP participants and associated cost savings. After participating in DEP, participants showed an average reduction in their A1c after 12 months. This outcome is comparable to A1c reduction reported in other DSMES studies. For example, a review of DSMES interventions observed A1c reduction of 0.88 percentage points for an intervention that involves both group and individual engagement [17]. This rate is slightly higher than the observed A1c reduction of group-based diabetes education programs and slightly lower than the observed A1c reduction of diabetes self-management programs delivered in community settings $[18,22,34-36]$.

The current study reports estimated healthcare cost savings associated with A1c reductions among DEP participants, as shown using two previously reported cost savings estimation methods [32, 33]. The total cost savings (i.e., \$5.4 million for two years) extrapolated based on the Bansal's estimation was higher than the amount 


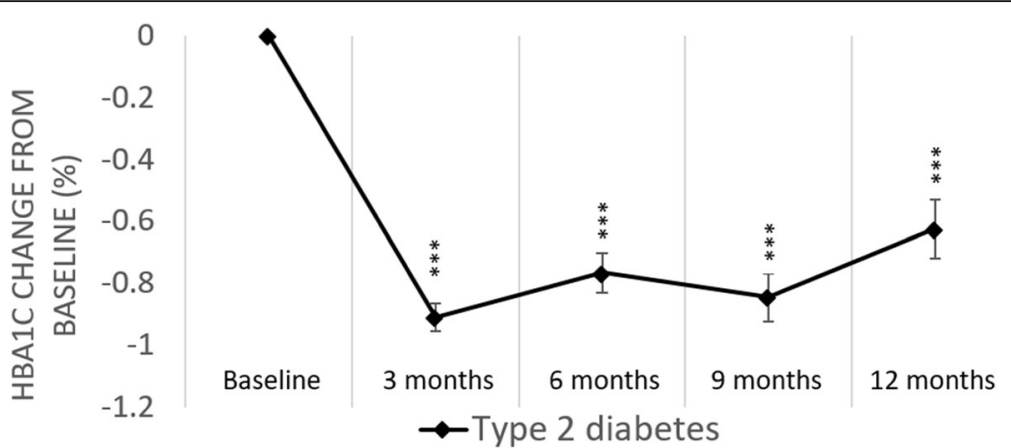

Fig. 2 Unadjusted A1c change from baseline at 3, 6, 9, and 12 months. (Statistically significant compared to baseline ${ }^{* *} P \leq 0.001{ }^{* *} P \leq 0.01{ }^{*} P \leq$ 0.05. Error bars indicate the standard error)

of cost saving extrapolated based on the Gilmer's estimation (\$5.8 million for three years). The reason for this difference points to the Bansal estimation utilizing cost savings of patients with baseline A1c levels $\geq 9$ percentage points [32] and the Gilmer estimation also including patients with baseline A1c levels $\leq 9$ percentage points [33]. Further, the magnitude of A1c reduction was reflected Gilmer's estimation, but not Bansal's estimation. Because Bansal did not fully present the cost savings estimation by the magnitude of A1c reduction, the mean cost savings was used (i.e., $\$ 2503$ for the first year and $\$ 1690$ for the second year) in the cost savings calculation in the current study. Considering the mean A1c reduction of 2.3 percentage points among the decreasers in the Bansal's study, and the mean A1c reduction of 0.73 to 0.93 percentage points in the current study, using the Bansal's estimation may have slightly overestimated the cost savings of A1c reduction from the DEP.

The estimated yearly healthcare cost savings for this DEP was about $\$ 830$ per participant (i.e., $\$ 2780 \times 1152 \div$ 3859 ) for the first year post DEP and $\$ 560$ (i.e., $\$ 1877 \times$ $1152 \div 3859)$ for the 2 nd year post DEP (i.e., $(\$ 2780+$ \$1877) $\div 2 \times 1152 \div 3859)$ using Bansal's estimation. Using Glimer's estimation, and healthcare cost saving per participant was estimated to be $\$ 1501$ over three years post DEP. While we were not able to report yearly cost savings, this is roughly equivalent with an average $\$ 500$ per person per year over three years (i.e., $\$ 1501$; 3). Given that the cost savings probably peak in the first year and attenuates over time, the first year post DEP cost saving is likely to be more than $\$ 500$ per person. These numbers are comparable to the estimated cost savings reported in the prior studies. For example, Turner and colleagues [35] examined 12-month preand post-education claims data for the Better Choices, Better Health diabetes program participants and found $\$ 815$ direct cost savings through the program and \$1504 indirect cost savings through the changes in related comorbid disease burden. Other studies that estimated cost savings of DSMES based on quality-adjusted life-years also showed potential economic benefits of DSMES [19, 37-39]. The current study estimated cost savings solely based on the A1c reduction; therefore, the estimated cost saving may underestimate the program impacts on the cost via enhanced quality of life and other comorbid disease burden. However, as stated by Turner and colleagues [35], not all DSMES are equal, and the economic benefits observed in this study may not be generalized to other programs or delivery settings. As such, further evaluation efforts are needed to generate more refined assessments of cost savings by population and delivery setting.

In the current study, the most dramatic A1c reduction occurred at 3-month follow-up, and the magnitude of A1c reduction decreased over time. While such tapering intervention effects can be common [40], this result may also be confounded by the potential bias associated with participant attrition and/or the effectiveness of the

Table 3 Adjusted $^{a}$ changes between baseline and follow-up means for improved health Outcomes

\begin{tabular}{|c|c|c|c|c|c|c|c|c|c|c|c|c|}
\hline & \multicolumn{3}{|c|}{ From Baseline to $3-\mathrm{mo}^{\mathrm{b}}$} & \multicolumn{3}{|c|}{ From Baseline to $6-\mathrm{mo}^{\mathrm{b}}$} & \multicolumn{3}{|c|}{ From Baseline to 9-mo ${ }^{b}$} & \multicolumn{3}{|c|}{ From Baseline to $12-\mathrm{mo}^{\mathrm{b}}$} \\
\hline & $\begin{array}{l}\text { Adjusted } \\
\text { Change }^{a}\end{array}$ & $\begin{array}{l}\text { Std. } \\
\text { Err. }\end{array}$ & $\mathbf{P}$ & $\begin{array}{l}\text { Adjusted } \\
\text { Change }^{\mathrm{a}}\end{array}$ & $\begin{array}{l}\text { Std. } \\
\text { Err. }\end{array}$ & $\mathbf{P}$ & $\begin{array}{l}\text { Adjusted } \\
\text { Change }^{\mathrm{a}}\end{array}$ & $\begin{array}{l}\text { Std. } \\
\text { Err. }\end{array}$ & $\mathbf{P}$ & $\begin{array}{l}\text { Adjusted } \\
\text { Change }^{\mathrm{a}}\end{array}$ & $\begin{array}{l}\text { Std. } \\
\text { Err. }\end{array}$ & $\mathbf{P}$ \\
\hline \multicolumn{13}{|c|}{ Type 2 diabetes } \\
\hline $\begin{array}{l}\text { Average } \\
\text { Alc }\end{array}$ & -0.926 & 0.045 & $<0.001$ & -0.832 & 0.058 & $<0.001$ & -0.870 & 0.070 & $<0.001$ & -0.731 & 0.091 & $<0.001$ \\
\hline
\end{tabular}

${ }^{a}$ All changes were adjusted for age, sex, race/ethnicity, education, language, insurance type, smoking, and drinking status

${ }^{\mathrm{b}}$ Adjusted changes between baseline and 3 months, 6 months, 9 months, and 12 months were from linear mixed regression models 
Table 4 Estimated direct medical cost savings from the program using the Bansal approach

\begin{tabular}{|c|c|c|c|c|c|c|}
\hline \multicolumn{3}{|c|}{$\begin{array}{l}\text { Number of Type } 2 \text { diabetes } \\
\text { participants at } 12 \text {-month }{ }^{\text {a }}\end{array}$} & \multicolumn{4}{|c|}{ Number of Type 2 Diabetes participants at baseline } \\
\hline \multicolumn{2}{|c|}{$\begin{array}{l}\text { - with baseline A1C > = } \\
9 \%\end{array}$} & 80 & \multicolumn{3}{|l|}{ - with baseline A1c > =9\% } & 1375 \\
\hline \multicolumn{2}{|c|}{$\begin{array}{l}\text { - A1c decreased at } 12- \\
\text { month }\end{array}$} & 67 & \multicolumn{3}{|c|}{ - A1c decreased at 12-month (extrapolated) } & 1152 \\
\hline \multicolumn{7}{|c|}{ Estimated cost savings from followed participants ( 12 month) in 2 years post training } \\
\hline $\begin{array}{l}\text { Direct } \\
\text { medical cost } \\
\text { savings }\end{array}$ & $\begin{array}{l}\text { 1st year } \\
(\text { per } \\
\text { patient })^{\mathrm{b}}\end{array}$ & $\begin{array}{l}\text { 2nd year } \\
(\text { per } \\
\text { patient) })^{b}\end{array}$ & $\begin{array}{l}\text { 1st year post DEP (based } \\
\text { on 12-month follow-up) }\end{array}$ & $\begin{array}{l}\text { 2nd year post DEP } \\
\text { (based on } 12 \text {-month } \\
\text { follow-up) }\end{array}$ & $\begin{array}{l}\text { 1st year post DEP } \\
\text { (estimated total program } \\
\text { saving) }\end{array}$ & $\begin{array}{l}\text { 2nd year post DEP } \\
\text { (estimated total program } \\
\text { saving) }\end{array}$ \\
\hline Medical & 2123 & 1236 & 142,241 & 82,812 & 2,445,696 & $1,423,872$ \\
\hline Inpatient & 510 & 476 & 34,170 & 31,892 & 587,520 & 548,352 \\
\hline Outpatient & 1597 & 743 & 106,999 & 49,781 & $1,839,744$ & 855,936 \\
\hline$-E R$ & 17 & 16 & 1139 & 1072 & 19,584 & 18,432 \\
\hline Pharmacy & 288 & 394 & 19,296 & 26,398 & 331,776 & 453,888 \\
\hline Others & 92 & 60 & 6164 & 4020 & 105,984 & 69,120 \\
\hline $\begin{array}{l}\text { Total }(2014 \\
\text { USD) }\end{array}$ & 2503 & 1690 & 167,701 & 113,230 & $2,883,456$ & $1,946,880$ \\
\hline $\begin{array}{l}\text { Total ( } 2018 \\
\text { USD) }\end{array}$ & 2780 & 1877 & 186,247 & 125,752 & $3,202,560$ & $2,162,179$ \\
\hline
\end{tabular}

${ }^{a}$ Estimates are from the program

b individual cost savings are from Bansal 2018 , cost saving only apply to patients with baseline A1c $>=9 \%$ and decreased compared to the ones with baseline A1c $>=9 \%$ and not decreased post index date

c program cost savings were estimated by multiplying per patient per year cost by the number of qualified program participants at 12 -month follow-up

d program cost savings were estimated by multiplying per patient per year cost by the estimated number of total qualified program participants

quarterly DEP follow-up sessions. For example, attrition may mitigate the tapering effects of an intervention because the healthiest participants may be most likely to remain over time. The high rates of participant attrition hold significant implications for DSMES in practice and research. In the current study, among those with Type 2 diabetes at baseline, $42 \%$ of participants had initial 3month follow-up data and less than 10\% had 12-month follow-up data. While the findings are encouraging for this DEP program, the findings should be interpreted in the context of a potential healthful bias related to program retention over time. One of the lessons learned from this intervention is that future efforts should emphasize the importance of program retention and aim to reduce barriers to follow-up and longer-term engagement with Type 2 diabetes participants. Tapering of

Table 5 Estimated direct medical cost savings from the program using the Gilmer approach

\begin{tabular}{|c|c|c|c|c|c|c|}
\hline \multicolumn{5}{|l|}{ A1c change from baseline in Type 2 diabetes patients at 12 months } & \multirow[b]{2}{*}{$\begin{array}{l}A 1 c \geq \\
10 \%\end{array}$} & \\
\hline Baseline A1c levels & $\begin{array}{l}\mathrm{A} 1 \mathrm{C}< \\
7 \%\end{array}$ & $\begin{array}{l}7 \% \leq \mathrm{A} 1 \mathrm{C} \\
<8 \%\end{array}$ & $\begin{array}{l}8 \% \leq \mathrm{A} 1 \mathrm{c} \\
<9 \%\end{array}$ & $\begin{array}{l}9 \% \leq \mathrm{A} 1 \mathrm{C}< \\
10 \%\end{array}$ & & \\
\hline No. of Type 2 diabetes participants with 12-mo follow-up & 133 & 78 & 47 & 27 & 53 & \\
\hline Average A1c change at 12-month follow-up (std. dev.) & $\begin{array}{l}0.15( \pm \\
0.73)\end{array}$ & $\begin{array}{l}-0.24( \pm \\
0.90)\end{array}$ & $\begin{array}{l}-0.45( \pm \\
1.68)\end{array}$ & $-1.37( \pm 1.55)$ & $\begin{array}{l}-2.9( \pm \\
2.56)\end{array}$ & \\
\hline Number of A1c decreasers & 58 & 50 & 32 & 22 & 45 & \\
\hline Number of A1c increasers & 64 & 24 & 14 & 5 & 8 & \\
\hline Number with no A1c change & 11 & 4 & 1 & 0 & 0 & \\
\hline Cost savings for $1 \%$ reduction & -514 & 373 & 1303 & 1374 & 1374 & \\
\hline Average cost savings per person by initial A1c level & -58 & -220 & -130 & 1057 & 3406 & \\
\hline \multirow[t]{2}{*}{ Program participants initial A1c distribution } & $28.9 \%$ & $20.5 \%$ & $14.9 \%$ & $11.6 \%$ & $24.0 \%$ & \\
\hline & \multicolumn{2}{|c|}{2002 USD } & & & & 2018 USD \\
\hline \multirow{3}{*}{$\begin{array}{l}\text { average cost savings per person (weighted) program saving in } 3 \text { years } \\
\text { based on } 12 \mathrm{~m} \text { follow-up } \\
\text { Estimated current program total cost saving in } 3 \text { years }\end{array}$} & \multicolumn{2}{|l|}{$\$ 859$} & & & & $\$ 1501$ \\
\hline & \multicolumn{2}{|c|}{$\$ 178,073$} & & & & $\$ 311,299$ \\
\hline & \multicolumn{2}{|c|}{$\$ 3,314,186$} & & & & $\$ 5,793,715$ \\
\hline
\end{tabular}


intervention effects and attrition issues may speak to the overall DEP structure or delivery, which may call for refined follow-up session formats to keep participants engaged and optimize support for A1c self-management. While there are many possible reasons for attrition over a 12-month intervention (e.g., perceived value of the intervention, competing demands for participant time and resources, participant relocation), program coordinators should remain diligent to engage participants more regularly during the 3-months between data collection and strategically employ incentives and rewards to keep participants interested in the program. This study used its findings to extrapolate cost savings to the broader participant base who enrolled in the intervention; however, future efforts should attempt to maximize participant retention over longer durations for more accurate economic evaluations.

\section{Limitations}

This study has several limitations. First, the high attrition rate was a significant finding, which prohibited obtaining A1c measures over time for all participants with baseline data and may have introduced bias. Attrition rates at 12-month follow-up were higher among younger participants, Hispanics, uninsured or Medicaidinsured, those with lower education, and those who engaged in smoking and alcohol consumption behaviors. While attrition is not unique to this study, especially given the relatively long timeline for follow-up, findings should be interpreted in light of this shortcoming. Second, the lack of a comparison group limited this study's ability to examine the direct effects of the program rather than potential effects from other factors. Despite the limitation, the naturalistic study approach (i.e., uncontrolled by researchers) provides valuable insights that can be transferred to actual program delivery in the field. Third, the cost savings in this study were extrapolated based on two prior studies of cost savings from A1c reduction [32, 33]. The differences between the current study population and the participants of the previous two studies may have influenced the estimates and extrapolation of cost savings. For example, Bansal's cost saving was estimated among those with a minimum of two years of commercial insurance or a Medicare Advantage plan during the study period. Bansal's study showed greatest cost saving from outpatient care and limited cost savings from emergency care. In the current study, about $20 \%$ were uninsured, and this population might have different patterns and rates of health service utilization and resulting healthcare costs. Rather than relying upon previous studies for healthcare utilization and cost-related information, future studies should access the participants' actual medical data (e.g., hospitalizations, emergency department visits, healthcare costs) to more accurately identify the effectiveness of interventions such as DEP. Finally, unlike cost-benefit studies that estimate both the cost of delivering the programs and cost saving from the program, this study did not estimate the cost of DEP delivery. Combined with higher attrition rates among younger participants, Hispanics, and less-resourced individuals (e.g., uninsured or Medicaid), the estimated cost savings should be considered with caution for informing dissemination decisions.

\section{Conclusion}

Findings support the benefits of DEP workshops with ongoing follow-up for sustained Type 2 diabetes risk management. In addition, study findings suggest significant potential cost savings as a result of improved blood glucose control among program participants. While this study is not without limitations, the findings indicate the potential of DEP and similar programs to reach more underserved and at-risk populations, such as the largely Hispanic population recruited in the current study. This study holds important implications for stakeholders seeking to ameliorate health disparities in diabetes and presents broader implications for potential cost savings for multiple public and private payers. Further work should be undertaken to investigate the program impacts based on direct measures of participant's health service utilization and healthcare cost and compare the program effectiveness by population characteristics and delivery settings.

\section{Abbreviations}

DEP: Diabetes Education Program; US: United States; ADA: American Diabetes Association; DSMES: Diabetes Self-Management Education and Support; HS: High School; GED: General Education Development

\section{Acknowledgments}

The authors would like to thank the Healthy South Texas team within the Texas A\&M Health Science Center for their work to deliver and evaluate this program. Special thanks is given to the Diabetes Education Program trainers, educators, and staff in Corpus Christi and McAllen who are continually dedicated to improving lives in South Texas. The authors would like to thank Starr Flores, Joe Flores, Olga Gabriel, Rose Lucio, Dr. Carrie Byington, and Dr. Susan Ballibina for their leadership role in the Healthy South Texas initiative. Additionally, the authors acknowledge that Dr. Samuel D. Towne, Jr. is an editorial board member of BMC Public Health, but his affiliation played no role in the review or editorial process with respect to this manuscript.

\section{Authors' contributions}

MLS conceptualized and wrote the manuscript. LZ performed all statistical analyses and wrote the manuscript. SL and SDT were major contributors in writing the manuscript. MGO critically reviewed the manuscript. All authors read and approved the final manuscript.

\section{Funding}

This research was supported in part by the State of Texas's legislative action to establish and support the Healthy South Texas initiative. Funds were administered through Texas A\&M University Health Science Center grant number 23-183000. The funding bodies played no role in the design of the study and collection, analysis, and interpretation of data and in writing the manuscript. 


\section{Availability of data and materials}

Public access to the database used in this study is closed. The data that support the findings of this study are available from the Coastal Bend Health Education Center; however, restrictions apply to the availability of these data, which were used under agreements for the current study, and so are not publicly available. Data are, however, available from the authors upon reasonable request and with permission of the Coastal Bend Health Education Center.

\section{Declarations}

\section{Ethics approval and consent to participate}

This study involved retrospective reviews and analyses of limited data from this community-based initiative and was reviewed and approved by the Institutional Review Board at Texas A\&M University (IRB2019-0225D). Administrative permission to access these data was given by the Coastal Bend Health Education Center.

\section{Consent for publication}

Not applicable.

\section{Competing interests}

The authors declare that they have no competing interests.

\section{Author details}

${ }^{1}$ Center for Population Health and Aging, Texas A\&M University, College Station, TX 77843, USA. ${ }^{2}$ Department of Environmental and Occupational Health, School of Public Health, Texas A\&M University, College Station, TX 77843, USA. ${ }^{3}$ College of Pharmacy, Texas A\&M University, College Station, TX 77843, USA. ${ }^{4}$ College of Nursing, University of Utah, Salt Lake City, UT 84112, USA. ${ }^{5}$ School of Global Health Management and Informatics, University of Central Florida, Orlando, FL 32816, USA. ${ }^{6}$ Disability, Aging, and Technology Cluster, University of Central Florida, Orlando, FL 32816, USA. ${ }^{7}$ Southwest Rural Health Research Center, Texas A\&M University, College Station, TX 77843, USA.

\section{Received: 6 October 2020 Accepted: 16 August 2021}

\section{Published online: 09 September 2021}

\section{References}

1. Centers for Disease Control and Prevention. National diabetes statistics report, 2020. Atlanta, GA: Centers for disease control and prevention, US Department of Health and Human Services; 2020.

2. Lin J, Thompson TJ, Cheng YJ, Zhuo X, Zhang P, Gregg E, et al. Projection of the future diabetes burden in the United States through 2060. Popul Health Metrics. 2018;16(1):1-9.

3. Hales $C M$, Carroll MD, Fryar CD, Ogden CL. Prevalence of obesity and severe obesity among adults: United States, 2017-2018. NCHS Data Brief. 2020;360.

4. Hispanic/Latino Americans and type 2 diabetes [Internet]. 2019 [cited September 20, 2020]. Available from: https://www.cdc.gov/diabetes/library/ features/hispanic-diabetes.html.

5. Adult obesity facts [Internet]. 2020 [cited September 20, 2020]. Available from: https://www.cdc.gov/obesity/data/adult.html.

6. Cheng YJ, Kanaya AM, Araneta MRG, Saydah SH, Kahn HS, Gregg EW, et al. Prevalence of diabetes by race and ethnicity in the United States, 20112016. JAMA. 2019;322(24):2389-98. https://doi.org/10.1001/jama.2019.19365.

7. Complications [Internet]. 2020 [cited September 20, 2020]. Available from: https://www.diabetes.org/diabetes/complications.

8. Trikkalinou A, Papazafiropoulou AK, Melidonis A. Type 2 diabetes and quality of life. World J Diabetes. 2017;8(4):120-9. https://doi.org/10.4239/ wjd.v8.14.120.

9. Jannoo Z, Wah YB, Lazim AM, Hassali MA. Examining diabetes distress, medication adherence, diabetes self-care activities, diabetes-specific quality of life and health-related quality of life among type 2 diabetes mellitus patients. J Clin Transl Endocrinol. 2017;9:48-54. https://doi.org/10.1016/j. jcte.2017.07.003.

10. Al-Rubeaan K, Youssef AM, Ibrahim HM, Al-Sharqawi A, AlQumaidi H, AlNaqeb D, et al. All-cause mortality and its risk factors among type 1 and type 2 diabetes mellitus in a country facing diabetes epidemic. Diabetes Res Clin Pract. 2016;118:130-9. https://doi.org/10.1016/j.diabres.2016.06.012.
11. Ohkuma T, Jun M, Hata J, Chalmers J, Woodward M, Williams B, et al. Prognostic Value of Variability in Systolic Blood Pressure Related to Vascular Events and Premature Death in Type 2 Diabetes Mellitus: The ADVANCE-ON Study. Hypertension. 2017;70(2):461-8.

12. The cost of diabetes [Internet]. 2020 [cited September 20, 2020]. Available from: https://www.diabetes.org/diabetes/complications.

13. Yang W, Dall TM, Beronjia K, Lin J, Semilla AP, Chakrabarti R, et al. Economic costs of diabetes in the US in 2017. Diabetes Care. 2018;41(5):917-28.

14. American Diabetes Association. 4. Lifestyle Management: Standards of Medical Care in Diabetes-2018. Diabetes Care. 2018;41:S38-50.

15. American Diabetes Association. 6. Glycemic Targets: Standards of Medical Care in Diabetes-2018. Diabetes Care. 2018;41:S55-64.

16. Carls G, Huynh J, Tuttle E, Yee J, Edelman SV. Achievement of Glycated Hemoglobin Goals in the US Remains Unchanged Through 2014. Diabetes Ther. 2017:8(4):863.

17. Chrvala CA, Sherr D, Lipman RD. Diabetes self-management education for adults with type 2 diabetes mellitus: a systematic review of the effect on glycemic control. Patient Educ Couns. 2016;99(6):926-43. https://doi.org/10.1 016/j.pec.2015.11.003.

18. Murphy ME, Byrne M, Galvin R, Boland F, Fahey T, Smith SM. Improving risk factor management for patients with poorly controlled type 2 diabetes: a systematic review of healthcare interventions in primary care and community settings. BMJ Open. 2017;7(8):e015135. https://doi.org/10.1136/ bmjopen-2016-015135.

19. Beck J, Greenwood DA, Blanton L, Bollinger ST, Butcher MK, Condon JE, et al. 2017 National Standards for diabetes self-management education and support. Diabetes Educ. 2020;46(1):46-61. https://doi.org/10.1177/014572171 9897952.

20. Powers MA, Bardsley J, Cypress M, Duker P, Funnell MM, Hess Fischl A, et al. Diabetes self-management education and support in type 2 diabetes: a joint position statement of the American Diabetes Association, the American Association of Diabetes Educators, and the Academy of Nutrition and Dietetics. J Acad Nutr Diet. 2015;8:1323.

21. Diabetes Self-Management Education and Support (DSMES) Toolkit: Return on investment [Internet]. 2018 [updated March 12, cited September 20, 2020]. Available from: https://www.cdc.gov/diabetes/dsmes-toolkit/businesscase/roi.html\#: :text=A\%20systematic\%20review\%20of\%20DSMES,who\%2 Odid\%20not\%20receive\%20DSMES.\&text=Other\%20studies\%20have\%2 Oindicated\%20that,people\%20with\%20type\%202\%20diabetes.

22. Steinsbekk A, Rygg LØ, Lisulo M, Rise MB, Fretheim A. Group based diabetes self-management education compared to routine treatment for people with type 2 diabetes mellitus. A systematic review with meta-analysis. BMC Health Serv Res. 2012;12(1):213. https://doi.org/10.1186/1472-6963-12-213.

23. Tshiananga JKT, Kocher S, Weber C, Erny-Albrecht K, Berndt K, Neeser K. The effect of nurse-led diabetes self-management education on glycosylated hemoglobin and cardiovascular risk factors a Meta-analysis. Diabetes Educ. 2012;38(1):108-23. https://doi.org/10.1177/0145721711423978.

24. U.S.Mexico Border Health Commission. Healthy border 2020: A prevention and health promotion initiative. El Paso, TX: U.S. Department of Health and Human Services; 2020.

25. Rosales CB, Carvajal SC, De Zapien G, Eileen J. Emergent public health issues in the US-Mexico border region. Front Public Health. 2016;4. https://doi. org/10.3389/fpubh.2016.00093.

26. Ramirez AG, Thompson IM, Vela L. In: Ramirez AG, Thompson IM, Vela L, editors. The South Texas Health Status Review : A Health Disparities Roadmap: Springer eBooks; 2013.

27. Kash BA, Lin S-H, Baek J, Ohsfeldt RL. The Diabetes Management Education Program in South Texas: An Economic and Clinical Impact Analysis. Front Public Health. 2017:5:345. https://doi.org/10.3389/fpubh.2017.00345.

28. Healthy South Texas. 2016-2017 Bi-annual Report. College Station, TX: Texas A\&M University; 2018.

29. Diabetes Education Program [Internet]. [cited September 20, 2020]. Available from: https://cbhec.tamhsc.edu/diabetes-education/index.html.

30. Ory MG, Lee S, Towne SD Jr, Flores S, Gabriel O, Smith ML. Implementing a diabetes education program to reduce health disparities in South Texas: application of the RE-AIM framework for planning and evaluation. Int J Environ Res Public Health. 2020;17(17):6312. https://doi.org/10.3390/ijerph1 7176312.

31. 2018 County Health Rankings [Internet]. 2020 [cited September 20, 2020]. Available from: https://www.countyhealthrankings.org/explore-health-ra nkings/use-data. 
32. Bansal M, Shah M, Reilly B, Willman S, Gill M, Kaufman FR. Impact of reducing glycated hemoglobin on healthcare costs among a population with uncontrolled diabetes. Appl Health Econ Health Policy. 2018;16(5):67584. https://doi.org/10.1007/s40258-018-0398-2.

33. Gilmer TP, O'Connor PJ, Rush WA, Crain LA, Whitebird RR, Hanson AM, et al. Predictors of health care costs in adults with diabetes. Diabetes Care. 2005; 28(1):59-64. https://doi.org/10.2337/diacare.28.1.59.

34. Lorig K, Ritter PL, Turner RM, English K, Laurent DD, Greenberg J. A diabetes self-management program: 12-month outcome sustainability from a nonreinforced pragmatic trial. J Med Internet Res. 2016;18(12):e322. https:// doi.org/10.2196/jmir.6484.

35. Turner RM, Ma Q, Lorig K, Greenberg J, DeVries AR. Evaluation of a diabetes self-management program: claims analysis on comorbid illnesses, health care utilization, and cost. J Med Internet Res. 2018;20(6):e207. https://doi. org/10.2196/jmir.9225.

36. Rickheim PL, Weaver TW, Flader JL, Kendall DM. Assessment of group versus individual diabetes education: a randomized study. Diabetes Care. 2002; 25(2):269-74. https://doi.org/10.2337/diacare.25.2.269.

37. Golden SH, Maruthur N, Mathioudakis N, Spanakis E, Rubin D, Zilbermint M, et al. The case for diabetes population health improvement: evidence-based programming for population outcomes in diabetes. Curr Diab Rep. 2017; 17(7):51. https://doi.org/10.1007/s11892-017-0875-2.

38. Odgers-Jewell K, Ball LE, Kelly JT, Isenring EA, Reidlinger DP, Thomas R. Effectiveness of group-based self-management education for individuals with type 2 diabetes: a systematic review with meta-analyses and metaregression. Diabet Med. 2017;8:1027.

39. Lian JX, McGhee SM, Chau J, Wong CKH, Lam CLK, Wong WCW. Systematic review on the cost-effectiveness of self-management education programme for type 2 diabetes mellitus. Diabetes Res Clin Pract. 2017;127:21-34. https:// doi.org/10.1016/j.diabres.2017.02.021.

40. Institute of Medicine. Living well with chronic illness: a call for public health action. England: Oxford University Press; 2015. Report No.: 180

\section{Publisher's Note}

Springer Nature remains neutral with regard to jurisdictional claims in published maps and institutional affiliations.

Ready to submit your research? Choose BMC and benefit from:

- fast, convenient online submission

- thorough peer review by experienced researchers in your field

- rapid publication on acceptance

- support for research data, including large and complex data types

- gold Open Access which fosters wider collaboration and increased citations

- maximum visibility for your research: over $100 \mathrm{M}$ website views per year

At BMC, research is always in progress.

Learn more biomedcentral.com/submissions 